\title{
The secretion of prostaglandin $F$ from the autotransplanted uterus of the ewe
}

\author{
R. J. Scaramuzzi*, D. T. Baird, H. P. Boyle, R. B. Land† \\ and A. G. Wheelert! \\ M.R.C. Unit of Reproductive Biology, Department of Obstetrics and Gynaecology, \\ University of Edinburgh, 39 Chalmers Street, Edinburgh EH3 9ER, \\ and \\ $\dagger$ A.R.C. Animal Breeding Research Organisation, \\ West Mains Road, Edinburgh EH9 3JQ, U.K.
}

Prostaglandin (PG) F-2 $\alpha$ is involved in a number of reproductive functions, including luteolysis (Goding, 1974) and menstruation (Pickles, Hall, Best \& Smith, 1965). Luteolysis in sheep is controlled by a local feedback loop operating between the uterus and the corpus luteum, and menstruation in primates is also directly controlled by the ovarian steroid hormones. A fuller knowledge of how these hormones influence the endometrium to produce and release PGF- $2 \alpha$ should lead to a better understanding of both luteolysis and menstruation.

In the present report we have examined the effects of oestradiol-17 $\beta$ and progesterone on the ability of the autotransplanted sheep uterus to release PGF into the uterine vein.

\section{Methods}

Three ovariectomized Tasmanian Merino (3/4) $\times$ Scottish Blackface (1/4) crossbred ewes were used. Before use the left uterine horn, body of the uterus, cervix and anterior vagina had been autotransplanted to a previously prepared site on the animal's neck (Baird, Land, Scaramuzzi \& Wheeler, 1976a). In this preparation the uterine artery and utero-ovarian vein are anastomosed to the left carotid artery and jugular vein, respectively, which are contained in separate skin loops. The viability of the transplanted organs was tested by angiography carried out at least 6 weeks after surgery (Baird et al., 1976a). Progesterone, when given, was administered as a series of twice daily i.m. injections each of $5 \mathrm{mg}$ in $0.5 \mathrm{ml}$ ethyl oleate. Oestradiol-17ß was administered as a continuous intraarterial infusion using the method described by Collett, Land \& Baird (1973) for LH infusions into the ovarian artery of ewes bearing ovarian autotransplants. The steroid was infused in $8 \%(v / v)$ ethanolic $\mathrm{NaCl}$ for $12 \mathrm{~h}$, and at a rate of $9.6 \mathrm{ml} / \mathrm{h}$. The concentration of oestradiol-17 $\mathrm{\beta}$ in the infusate was adjusted according to estimated uterine blood flow to achieve a concentration of 3.9-10.2 (mean $6.7) \mathrm{pg} / \mathrm{ml}$ in the uterine artery. This was the maximum concentration of oestradiol calculated to be present in carotid arterial blood of the ewe during pro-oestrus (Baird, McCracken \& Goding, 1973). Preliminary tests had shown glass syringes and thin-wall Teflon tubing produced insignificant losses of oestradiol-17 $\beta$ by absorption from the infusion solution. Timed samples $(25 \mathrm{ml})$ of uterine venous blood were collected through a nylon catheter (i.d. $1.5 \mathrm{~mm}$, o.d. $2.1 \mathrm{~mm}$, No. B205: Portex Ltd, Hythe, Kent) using Method $a$ described by Baird et al. (1976b). Samples were collected every $1 \mathrm{~h}$ for $24 \mathrm{~h}$ ( 4 experiments) or every $2 \mathrm{~h}$ for $48 \mathrm{~h}$ (13 experiments). Samples were chilled and centrifuged at $4^{\circ} \mathrm{C}$ immediately after collection and the plasma was removed and stored at $-20^{\circ} \mathrm{C}$ until assay. All plasma samples were assayed within 3 months of collection. Prostaglandin levels were measured using the radioimmunoassay described by Caldwell, Tillson, Brock \& Speroff (1972) and as previously reported from this laboratory (Baird et al., 1976b; Land, Baird \& Scaramuzzi, 1976).

\footnotetext{
* Present address: C.S.I.R.O., Division of Animal Production, P.O. Box 239, Blacktown, N.S.W. 2148, Australia. $\ddagger$ Present address: Department of Anatomy, University of Birmingham Medical School, Birmingham B15 2TS, U.K.
} 


\section{Results and discussion}

The basal concentration of PGF in the uterine vein of an unstimulated long-term ovariectomized ewe in 4 experiments ( $108 \pm 8$ (S.E.M.) pg/ml, $n=76$ ) was not significantly different (by $t$ test) from the concentrations of PGF in jugular venous blood $(109 \pm 10 \mathrm{pg} / \mathrm{ml}, n=12)$ or carotid arterial blood $(72 \pm 7 \mathrm{pg} / \mathrm{ml}, n=7)$. The basal pattern gave no evidence of episodic discharges or a diurnal rhythm of PGF release.

In two experiments when oestradiol was infused into the uterine artery in physiological concentrations there was no rise in the concentration of PGF and the slight increase seen in the $6 \mathrm{~h}$ after infusion was not statistically significant (Text-fig. 1B). However, when progesterone was injected daily for 7 or 14 days there was a significant $(P<0.05, t$ test) increase in mean concentration of PGF compared to that of untreated controls (Text-fig. 1A), although the levels after 14 days were lower $(P<0.05)$ than those after 7 days of progesterone treatment.

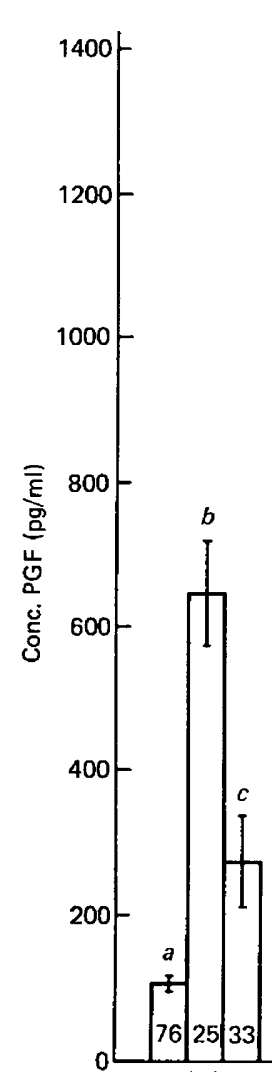

(A)

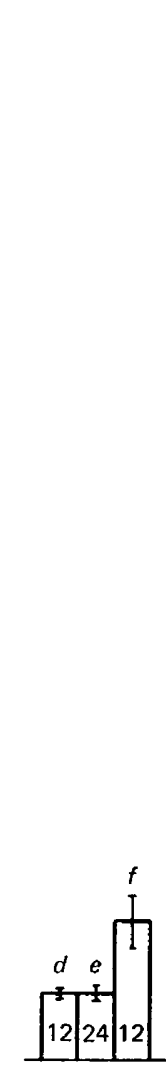

(B)

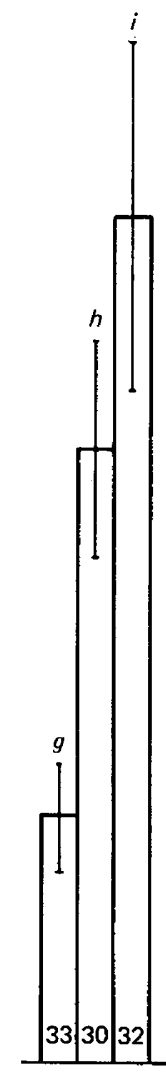

(C)

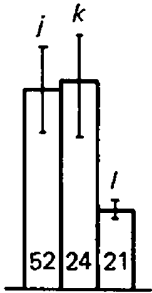

(D)

Text-fig. 1. The mean concentrations $(\mathrm{pg} / \mathrm{ml})$ of PGF in uterine venous blood of ovariectomized ewes bearing a uterine autotransplant. The vertical bars indicate the S.E.M. and the total number of observations pooled over several experiments and times of collection are shown at the base of each column. (A) Sheep received (a) no treatment ( 4 experiments) or progesterone $(5 \mathrm{mg}$ every $12 \mathrm{~h}$ ) for $(b) 7$ days $(2$ experiments) or (c) 14 days (5 experiments). Results are arranged over a $24-h$ period. (B) Mean concentrations for $(d) 6 \mathrm{~h}$ before, $(e)$ during and $(f) 6 \mathrm{~h}$ after a 12-h infusion of oestradiol-17ß (see text) (2 experiments). (C) Mean concentration for $(g, j) 12 \mathrm{~h}$ before, $(h, k)$ during and $(i, l) 12 \mathrm{~h}$ after a 12 -h infusion of oestradiol-17 $\beta$ (see text) given $48 \mathrm{~h}$ after the end of a 14-day progesterone pretreatment schedule ( 5 experiments). (D) As for (C) except that progesterone pretreatment was continued up to and during the oestradiol-17 $\beta$ infusion (4 experiments). 
The results of experiments involving the intra-arterial infusion of oestradiol-17 $\beta$ after progesterone pretreatment are shown in Text-fig. 1(C). The concentration of PGF rose $(P<0.05)$ during the infusion and increased further after infusion $(P<0.05)$. Although not apparent from the pooled data in Text-fig. 1(C) the concentration of PGF slowly returned to basal levels 10-12 $\mathrm{h}$ after the end of the infusion. When the progesterone pretreatment ( $5 \mathrm{mg}$ every $12 \mathrm{~h}$ ) was continued up to and during the oestradiol-17 $\beta$ infusion the mean concentration of PGF did not increase during the oestradiol-17 $\beta$ infusion and was significantly decreased $(P<0.05)$ in the $12 \mathrm{~h}$ after infusion when compared to the mean concentrations of PGF in the preinfusion period (Text-fig. 1D).

Earlier reports have shown that ovariectomized ewes treated with progesterone and oestrogen had increased levels of PGF in jugular venous (Caldwell et al., 1972) or uterine venous blood (Ford et al., 1975; Harrison \& Heap, 1975). The present results confirm and extend these findings. In the long-term ovariectomized ewe virtually no prostaglandin $\mathrm{F}$ was released into the uterine vein and short-term oestrogen treatment produced a slight but non-significant increase in PGF concentration in the uterine vein (Text-fig. 1B). The same quantity of oestrogen when administered after a period of progesterone pretreatment caused a massive release of PGF (Text-fig. 1C). Progesterone given alone for 7 days can stimulate the endometrium to release more PGF when compared to no progesterone treatment or to 14 days of progesterone treatment (Text-fig. 1A). However, it has been reported that exogenous progesterone decreased the content and concentration of PGF-2 $\alpha$ in the ovine endometrium (Wilson, Butcher, Cenedella \& Inskeep, 1972), and in the present experiment progesterone antagonized the action of oestradiol-17 $\beta$ in stimulating PGF release into the uterine vein (Text-fig. 1D). These paradoxical effects of progesterone require additional investigation.

Barcikowski, Carlson, Wilson \& McCracken (1974) found that oestradiol stimulated the release of PGF if infused into the uterine artery on Day 14 but not on Days 6 or 10 of the cycle. However, the calculated concentration of oestradiol in the uterine artery $(20 \mathrm{pg} / \mathrm{ml})$ was up to 7 -fold greater than the maximum observed in the jugular venous blood of ewes during the preovulatory period (Scaramuzzi \& Land, 1976) and at least twice those used in the present study. In the normal oestrous cycle PGF is released into the uterine vein in increasing amounts after Day 12 (Baird et al., 1976b). Our results support the view that this initial release of PGF is in response to secretion of progesterone by the corpus luteum for 7-10 days and that further release is facilitated by the subsequent fall of progesterone levels and the rise in secretion of oestradiol from the preovulatory follicle.

We thank Mr W. G. Davidson for expert technical assistance.

\section{References}

Baird, D.T., MCCRACken, J.A. \& Goding, J.R. (1973) Studies in steroid synthesis and secretion with the autotransplanted sheep ovary and adrenal. In The Endocrinology of Pregnancy and Parturition, pp. 5-16. Ed. C. G. Pierrepoint. Alpha Omega Alpha, Cardiff.

BaIRD, D.T., LAND, R.B., SCARAmuzzI, R.J. \& WheEler A.G. (1976a) Functional assessment of the autotransplanted uterus and ovary in the ewe. Proc. $R$. Soc. B 192, 463-474.

Batrd, D.T., LAND, R.B., Scaramuzzi, R.J. \& WheEler, A.G. (1976b) Endocrine changes associated with luteal regression in the ewe; the secretion of ovarian oestradiol, progesterone and androstenedione and uterine prostaglandin $F_{2 \alpha}$ throughout the oestrous cycle. J. Endocr. 69, 276-285.

Barcikowski, B., Carlson, J.C., Wilson, L. \& MCCRACKen, J.A. (1974) The effect of endogenous and exogenous estradiol-17 $\beta$ on the release of prostaglandin $F_{2 \alpha}$ from the ovine uterus. Endocrinology 95, 1340-1349.
Caldwell, B.V., Tillson, S.A., Brock, W.A. \& SPEROFF, L. (1972) The effects of exogenous progesterone and estradiol on prostaglandin $F$ levels in ovariectomized ewes. Prostaglandins 1, 217-228.

Collett, R.A., LAND, R.B. \& Baird, D.T. (1973) The pattern of progesterone secretion by the autotransplanted ovary of the ewe in response to ovine luteinizing hormone. J. Endocr. 56, 403-411.

Ford, S.P., Weems, C.W., Pitts, R.E., Pexton, J.E., Butcher, R.L. \& INSKEEP, E.K. (1975) Effects of estradiol-17 $\beta$ and progesterone on prostaglandins $F$ in sheep uteri and uterine venous plasma. $J$. Anim. Sci. 41, 1407-1413.

GodiNG, J.R. (1974) The demonstration that PGF $2 \alpha$ is the uterine luteolysin in the ewe. J. Reprod. Fert. 38, 261-272.

Harrison, F.A. \& Heap, R. B. (1975) Prostaglandin secretion by the autotransplanted uterus in sheep. J. Endocr. 64, 13-14P.

LAND, R.B., BaIRD, D.T. \& SCARAMUZzI, R.J. (1976) Dynamic studies of prostaglandin F-2 $\alpha$ in the utero- 
ovarian circulation of the sheep. J. Reprod. Fert. levels during the oestrous cycle: a comparison of 47, 209-214.

Pickles, V.R., Hall, W.J., Best, F.A. \& Smith, G.N. 3 breeds of different fecundity. Theriogenology (in press).

(1965) Prostaglandins in endometrium and menstrual Wirson, L., Butcher, R.L., CEnisdilla, R.J. \& fluid from normal and dysmenorrhoeic subjects. J. Obstet. Gynaec. Br. Commonw. 72, 185-192.

Scaramuzzi, R.J. \& LAND, R.B. (1976) Oestradiol INSKREBP, E.K. (1972) Effects of progesterone on endometrial prostaglandins in sheep. Prostaglandins 1, 183-189.

Recelved 29 June 1976 